\title{
The Evolution of Wages in the United Kingdom: Evidence from Micro Data
}

\author{
Costas Meghir, Institute for Fiscal Studies and \\ University College London \\ Edward Whitehouse, Organization for Economic \\ Cooperation and Development
}

\begin{abstract}
We use data on male employees from the U.K. Family Expenditure Survey for the years 1968-86 to investigate the behavior of wages over time and across cohorts. We find that differentials between manual workers and professional managerial ones are lower at labor market entry for younger cohorts but increasing faster with age in the 1980s than in the past. The returns to experience appear to be very low in the United Kingdom, particularly for manual and clerical workers, although the improved education of younger workers may partly explain this. Finally we show that individual wages in the United Kingdom are highly procyclical.
\end{abstract}

\section{Introduction}

The evolution of wages for different groups in the population has attracted a large amount of interest recently, mainly because of the observed

The comments of John Pencavel helped us improve this article substantially. We would also like to thank Richard Blundell, Andrew Dilnot, Richard Disney, Amanda Gosling, Mark Stewart, Frank Vella, Ian Walker, Guglielmo Weber, and seminar participants at McMaster University, the Centre for Economic Performance at the London School of Economics, and the Labor Study group conference at the University of Kent at Canterbury in 1991 for helpful discussions and suggestions. We are grateful to the Institute for Fiscal Studies and the Department of Employment for providing Family Expenditure Survey data and the Economic and Social Research Council for funding the Research Centre for Fiscal Policy, grant W100281002. All errors are ours alone.

[Journal of Labor Economics, 1996, vol. 14, no. 1]

(C) 1996 by The University of Chicago. All rights reserved.

0734-306X/96/1401-0002\$01.50 
increases in wage and income dispersion. The explanations in the United States have focused on changing returns to education on the effects of technical change and on the effects of increasing product market competition on the returns to skill. ${ }^{1}$

In characterizing the way the wage distribution evolves, it is important consider the effects of new cohorts of individuals entering the labor market while old ones retire. It is not necessarily true that cohorts are perfectly substitutable for each other. Cohorts differ by their size and by the quality and amount of education that they have received; the latter is partly governed by the compulsory schooling laws in force at the time and by the content of the curriculum, which may develop skills complementary to new production techniques. For these reasons productivity growth at any point in time may not be distributed equally across cohorts, and hence the life-cycle profiles of their wages may be different. These factors may induce changes in the distribution of wages that can be interpreted as cohort effects.

To characterize what has been happening to wages in the United Kingdom, we estimate wage equations as a function of age, occupation, and business cycle variables for separate birth cohorts of individuals. Our sample is drawn from the U.K. Family Expenditure Survey, a time series of repeated cross sections, for the years 1968-86, and it comprises all male employees between the ages of 22 and 59 inclusive. Our wage measure is the hourly wage rate, which we believe both best reflects individual productivity and abstracts from the effects of hours of work. This is very important because male average hours of work have fallen considerably over our sample period.

In the wage equations we control for occupation, the distribution of which varies over time, within and across cohorts. This reflects promotions over the life cycle and skill upgrading across generations. We define two occupational groups, based on the Family Expenditure Survey classification: one including those recorded as professional (including teachers) and managerial workers, the other including manual and clerical workers and shop assistants.

Our results show that the cross-section profile of wages against age is particularly flat for the manual/clerical group (which constitutes over $60 \%$ of the sample) throughout the sample period. This implies either that the returns to experience are nonexistent for this group or that they are very closely counteracted by cohort effects that may reflect an upgrading of the manual/clerical groups. In contrast, we identify significant returns to experience for the professional/managerial group early in labor market life. Since there has been a significant increase in the proportion of professional/

${ }^{1}$ See Bound and Johnson (1992) and Murphy and Welch (1992) for the United States and Schmitt (1992) for the United Kingdom. 
managerial workers over time within each birth cohort, we also consider the implied returns to experience for the entire population, and we show that, except early in labor market life, the returns to experience, implied by the cross-sectional differences across cohorts, seem to be very low (or counteracted by cohort effects) even for the entire sample.

The pay differentials between professional and managerial workers on the one hand and manual/clerical workers on the other have fallen across cohorts but rise with time for the younger cohorts during the 1980s. The fall in the differential early in working life for the younger cohorts may be a consequence of the increase in the proportion of professional/managerial workers and of the improved educational attainment of the manual/ clerical groups making the latter more substitutable for the former at young ages. The main implication of our results is that the increase in wage dispersion in the United Kingdom has taken place within the group of manual/clerical workers. The divergence of pay between the two occupational groups is only a small contributing factor.

Many authors have raised the issue of self-selection into occupations. It is important for a clear interpretation of events as well as for the design of effective labor market policies to distinguish the direct effects of occupational choice on hourly earnings from those arising purely from a correlation between occupation type and unobserved characteristics affecting productivity. To see this, suppose we find that pay differentials between the occupation groups are increasing and that this is partly responsible for increased wage dispersion. If controlling for self-selection reduces the pay differential, then part of the increase can be interpreted as being driven by a general increase in the demand for high-ability people permeating all occupations. Occupational pay differentials in this case are partly driven by the fact that some occupations contain a larger number of higher-ability individuals. If, however, we find that self-selection does not bias the occupational differentials, we can interpret the results as implying that changing pay differentials result directly from an increase in the demand for individuals in the professional/managerial occupations. In this case, increased differentials are less likely to persist since the supply of such workers will tend to increase, as education and occupation choices adjust.

Using grouped cohort data, rather than individual observations, we can control for the effects of self-selection into occupations by exploiting the changing occupational choices over time since grouping averages out the idiosyncratic unobservable productivity components which may be correlated with occupation. We can then compare the results to those obtained using the original cross-section data and test the hypothesis that the latter do not reflect unobserved productivity effects. Grouping has the additional advantage that it can average out additive measurement error arising by random-miss classification into occupations. When we group the data, the 
effects of characteristics that are fixed over time (such as education) are accounted for by the cohort effects.

This article is organized as follows. Section II describes our approach to the empirical specification of the wage equation. The estimation method-using grouped averages rather than the underlying individual cross-section observations-is outlined in Section III. The data are described in the following section, and the regression results presented in Sections $\mathrm{V}$ and VI. Section VII concludes.

\section{The Empirical Specification for the Wage Equation}

The analysis uses 19 years of repeated cross sections from 1968 to 1986, and we follow the experience of four different birth cohorts: those born in the 1920s, the 1930s, the 1940s, and the 1950s. We allow for cohort effects to control for generation-specific factors such as the level, quantity, and content of education and the size of the cohort. ${ }^{2}$ The effects of cohort need not be constant with age since events in the past may not have a permanent effect on the individual's experience profile. The unit of time is one quarter of a year. The empirical specification of the wage equation for cohort $c$ is given by

$$
\begin{aligned}
\ln w_{i t}= & \beta_{0}^{c}+\beta_{1}^{c} \text { trend }+\beta_{2}^{c} \text { trend }{ }^{2}+\beta_{3}^{c} \text { trend }^{3}+\beta_{4}^{c} \text { spline } \\
& \left.+\delta_{0}^{c} \text { (manual } / \text { clerical }\right)+\delta_{1}^{c}(\text { manual } / \text { clerical }) \times \text { trend } \\
& +\gamma \text { unemployment }+\varepsilon_{i t},
\end{aligned}
$$

where $\ln w_{i t}$ is the log of the real hourly wage rate. All coefficients are cohort-specific except for the coefficient on the unemployment rate $(\gamma)$, which is constrained to be common across cohorts. ${ }^{3}$ Using the aggregate unemployment rate as our cyclical demand indicator makes our work comparable in this respect to Bils (1985), Keane, Moffitt, and Runkle (1988), and Blank (1990) for the United States and Blanchflower and Oswald (1994) for the United Kingdom. To examine whether the cyclical properties of wages are different between occupations, we include an interaction between the unemployment rate and a dummy variable equal to one when an individual is a manual or clerical worker and zero when he is a profes-

${ }^{2}$ Note that we observe education in our data only after 1977, and we thus cannot explicitly control for the different educational composition of the cohorts.

${ }^{3}$ In earlier results we found that the coefficient on the unemployment rate was virtually the same for the two middle cohorts that are observed for the entire sample period and quite badly determined for the 1920s and the 1950s cohort, both of which are observed for a shorter period of time. As a result we decided there was nothing to be gained by allowing the coefficient on the unemployment rate to vary across cohorts. 
sional or managerial worker. ${ }^{4}$ The age profiles estimated for the wages of each cohort should be interpreted as unconditional age effects reflecting the influence of experience and general productivity growth on a specific cohort and occupation. (Note that trend is a variable ranging from -36 in the first quarter of 1968 to 39 in the last quarter of 1986.) The variable spline is defined as (trend +2$)^{3}$ if trend $>-2$ (i.e., from 1977) and zero otherwise. We constrained the trend polynomial to be linear for the $1920 \mathrm{~s}$ cohort $\left(\beta_{2}^{c}=\beta_{3}^{c}=\beta_{4}^{c}=0\right.$ for $\left.c=1\right)$ and quadratic for the 1950s cohort $\left(\beta_{3}^{c}=\beta_{4}^{c}=0\right.$ for $\left.c=4\right) .^{5}$ After some specification search, we excluded interactions of the manual/clerical dummy variable with higher-order trend polynomials, except for the 1940s cohort.

The unobserved attributes affecting productivity and shocks to wages are subsumed in $\varepsilon_{i t}$. These may be correlated with occupation, with implications for the interpretation of the results as discussed in the introduction.

The residuals in the wage equation may also be correlated across individuals as they may contain a common shock affecting wages. This raises the issue of whether the unemployment rate is endogenous for the wage equation since common shocks to wages may feed back in to unemployment. This will affect the interpretation of all the coefficients, including the one on the unemployment rate. We report results based on the assumption that the unemployment rate is exogenous and results where the aggregate unemployment rate is instrumented. We use the lagged U.S. unemployment rate as an instrument for the current U.K. rate. The validity of the instrumental variables procedure is of course conditional on the functional form assumptions we have imposed for the age profiles. The rationale for the use of the U.S. unemployment rate as an instrument is that the business cycle in the United States is likely to affect economic activity in the United Kingdom through the trade links between the two countries and hence lead to changes in U.K. unemployment rates. Since migration between the two countries is limited by explicit restrictions on work permits as well as by the distance between the two countries, we do not expect U.S. unemployment rates to affect U.K. wages directly. As we report in the empirical section, the U.S. unemployment rate is highly significant in the reduced form for the U.K. unemployment rate. Finally, when we compute standard errors, we allow for correlated shocks across individuals in all cases.

${ }^{4}$ The group of clerical workers is small and stable over time with pay very similar to the skilled manual workers. Moreover, they have a similar educational background. This is why we decided to group them with the manual workers.

${ }^{5}$ Since time $=$ cohort + age, and since each trend polynomial is cohort-specific, these are identical to age polynomials. We have used trend rather than age for convenience because we will be plotting the wage profiles for different cohorts against time. No substantive difference is involved. 
We now turn to a brief description of our econometric method; the details are relegated to the appendix.

\section{Grouping by Cohorts and Estimation}

To distinguish the effects of occupation from the effects of unobserved productivity, we estimate the model by aggregating the individual level wages by cohort and time. This forms a pseudopanel of cohorts. The dependent variable becomes the average $\log$ real wage for cohort $c$ in period $t$; the right-hand-side variables are as in equation (1), but the manual/ clerical indicator is replaced by the proportion of manual/clerical workers in the cohort at time period $t$. The virtue of the method lies in the fact that the aggregation procedure averages out (in sufficiently large samples) the idiosyncratic elements in the error term, including any additive measurement error, which may be correlated with the included regressors such as occupation. Only the common (aggregate) shocks remain after such aggregation. The procedure, which is based on Wald (1940), is developed by Heckman and Robb (1987) to measure treatment effects. ${ }^{6}$ As we show in the appendix, the method has an interpretation as an instrumental variables estimator with the instruments being the cohort indicators interacted with the time indicators.

Once the data have been grouped, we may still wish to apply instrumental variables at the aggregated level to purge the correlation of some regressors with the aggregate shock. In our case, we instrument the current unemployment rate with lagged U.S. unemployment. The precise formulae for the estimators and their covariance matrix are given in the appendix.

The grouped model results can be compared with the results obtained directly from the cross section and a formal Wu-Hausman test can be performed to test for the equality of the coefficients between the two procedures (see also Farebrother 1979). For the sake of comparability, the standard errors at the cross-section regression must also allow for the presence of aggregate shocks.

The model with grouping is identified to the extent that the mean of the explanatory variables change sufficiently between cohorts and time (i.e., data cells). In addition we have to assume that we can exclude (some) cohort effects interacted with time effects from the estimating equation. Finally we either need to assume that the parameters of interest are constant across cohort and time or we have to model the way the parameters change between these groups in a sufficiently parsimonious way (see also Heckman and Robb [1987] on this issue).

\footnotetext{
${ }^{6}$ See also Deaton (1985) and Angrist (1991), among others.
} 
Table 1

Structure of the Grouped Data Taken from the Family Expenditure Survey

\begin{tabular}{lcccc}
\hline Cohort & Date of Birth & $\begin{array}{c}\text { Period of } \\
\text { Observation }\end{array}$ & $\begin{array}{c}\text { Average } \\
\text { Cell Size }\end{array}$ & $\begin{array}{c}\text { Minimum } \\
\text { Cell Size }\end{array}$ \\
\hline $1920 \mathrm{~s}$ & $1919-28$ & $1968-78$ & 249 & 165 \\
$1930 \mathrm{~s}$ & $1929-38$ & $1968-86$ & 218 & 145 \\
$1940 \mathrm{~s}$ & $1939-48$ & $1970-86$ & 263 & 174 \\
$1950 \mathrm{~s}$ & $1949-58$ & $1980-86$ & 253 & 216 \\
\hline
\end{tabular}

NOTE.--Cell Size is the number of individuals per cohort per quarter.

We group the data into four broad date-of-birth cohorts, each covering 10 years. This is done to make sure that we are averaging over a sufficiently large number of individuals in each cohort per period?

\section{A Descriptive Analysis of the Evolution of Wages}

The data are drawn from the U.K. Family Expenditure Survey for the years $1968-86$. The overall sample size is 53,495 . We have selected all men between the ages of 22 and 59, inclusive, who are not self-employed or retired. ${ }^{8}$ To construct our grouped data set, we have divided each quarter year's observations into 10-year date-of-birth bands, the first starting in 1919 , and then averaged the relevant variables over the quarter within the cohort. This gives an unbalanced pseudopanel of 4 cohorts and 72 quarterly observations, and a total of 216 grouped observations. The structure of the grouped data is given in table 1.

The nominal wage was constructed by dividing usual weekly earnings (including usual overtime pay) by usual weekly hours (including usual overtime hours). To obtain the real wage, we deflate individual wages by the monthly retail price index.

7 This point can be interpreted as saying that we must not use too large a number of instruments to avoid overfitting the endogenous variable. The trade-off between robustness and efficiency in the choice of the breadth of the groups is a small sample problem that needs to be investigated. Asymptotically it becomes irrelevant if we assume that as the sample becomes larger the number of individuals in each of the predefined groups increases.

${ }^{8}$ The official retirement age for men is 65 , but early retirement is quite prevalent. By restricting our sample to those with age less than 60 , we attempt to mitigate the composition effects induced by early retirement. Similarly, we do not consider men younger than 22 because we want to make sure that all (or most) members of the cohort are out of full-time education. We recognize that selecting out the self-employed may introduce some composition bias particularly during the 1980s, where a relatively large number of workers moved to self-employment. The data on incomes seem to suggest that these are low-productivity individuals (see Goodman and Webb 1994). There is little we can do to correct for this composition bias here. 
Figure $1 a$ presents a smoothed age profile of log wages for each cohort for the entire sample. Wages grow with age for any given cohort, but each new cohort starts up from a higher point. It is revealing to replot the same data against time but still distinguish the separate cohorts, as shown in figure $1 b$. There are two interesting features of this graph. First, both cohorts observed relatively close to labor market entry (the 1940s in 1970 and the 1950 s in 1980) enter at a lower wage than the workers of the previous cohort (15\% and $12 \%$, respectively). The 1940 s cohort catches up quite fast, but the wages of the 1950s cohort remain lower for longer. Second, apart from these points, the difference of wages across any two cohorts is very small and often zero. Average real wages of the 1930s and the 1940s
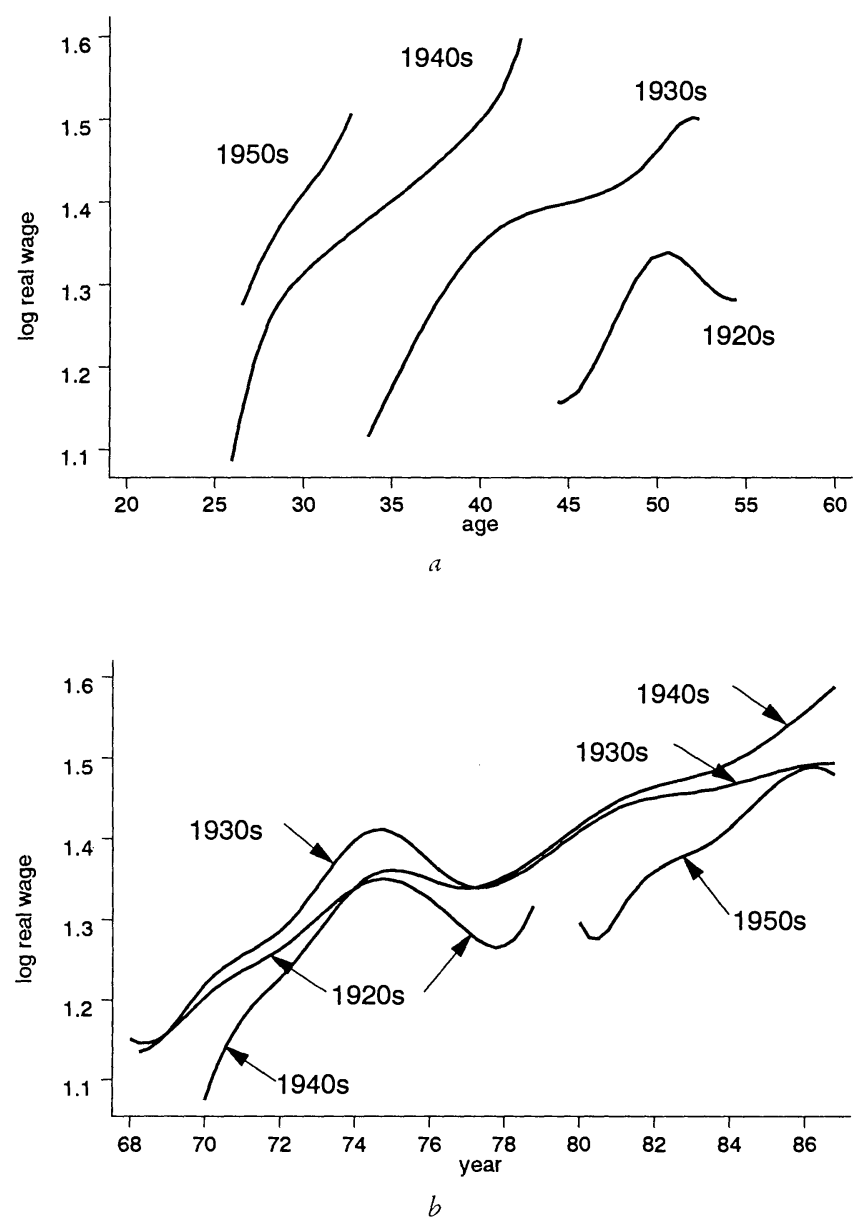

FIG. 1.-Log hourly wages. $a$, By cohort and age; $b$, by cohort and year. 
cohorts are virtually the same after 1976. These cross-section differences result both from experience and cohort effects, which may counteract each other. Finally note that the fall in real wages for all cohorts in 1977 corresponds to the end of the Social Contract under which a series of incomes policy was implemented by the Labour Party government. It also coincides with a substantial increase in the unemployment rate.

To gain further insight, we split the sample into the two occupation groups defined above, and plot them separately against time in figures $2 a$ and $2 b$. The average wages of manual/clerical workers (fig. $2 a$ ) are approximately the same at each point in time, irrespective of date of birth, despite the 10-year average age difference between successive cohorts. Experience profiles are totally flat for manual/clerical workers, conditional on their not moving to professional or managerial occupations. In particular, the entry effect on the wages of the whole sample is absent for manual/ clerical occupations. The small cross-section age differences in wages we observed for the entire population are due to the behavior of wages for professional/managerial workers (fig. $2 b$ ). If wage growth due to experience coincides with occupational upgrading, this could just be a composition effect. However, the largest cross-section differences occur for the professional/managerial workers between new entrants and incumbents rather than later in life. This is evidence against the composition interpretation.

The data suggest that the returns to experience for manual/clerical workers (as reflected by the differences of the wages of separate cohorts at the same point in time) are either very low or counteracted by cohort effects. For the professional/managerial workers, these cross-section differences are only important early in working life. To shed further light on this pattern, table 2 shows the average age at which workers in each cohort left full-time education, by occupation. ${ }^{9}$ There have been two reforms affecting the minimum quantity of schooling. The minimum schoolleaving age was raised from 14 to 15 in 1948 (affecting individuals born after 1934), and to 16 in 1973 (affecting only a few individuals in our sample). Table 2 shows that later cohorts have more education, and this is true for both occupation groups. This may partly explain why older manual/clerical workers are not paid more than younger workers at any moment in time, if the returns to increased education offset experience effects. Nevertheless, the substantial increases in the education of the professional/managerial group do not seem to have eliminated the difference in wages between incumbents and labor market entrants. This may be related to the increase in the proportion of professional/managerial workers, as we document below.

${ }^{9}$ This education measure is observed only from 1978 onward and so cannot be used as a control in our regression analysis. 

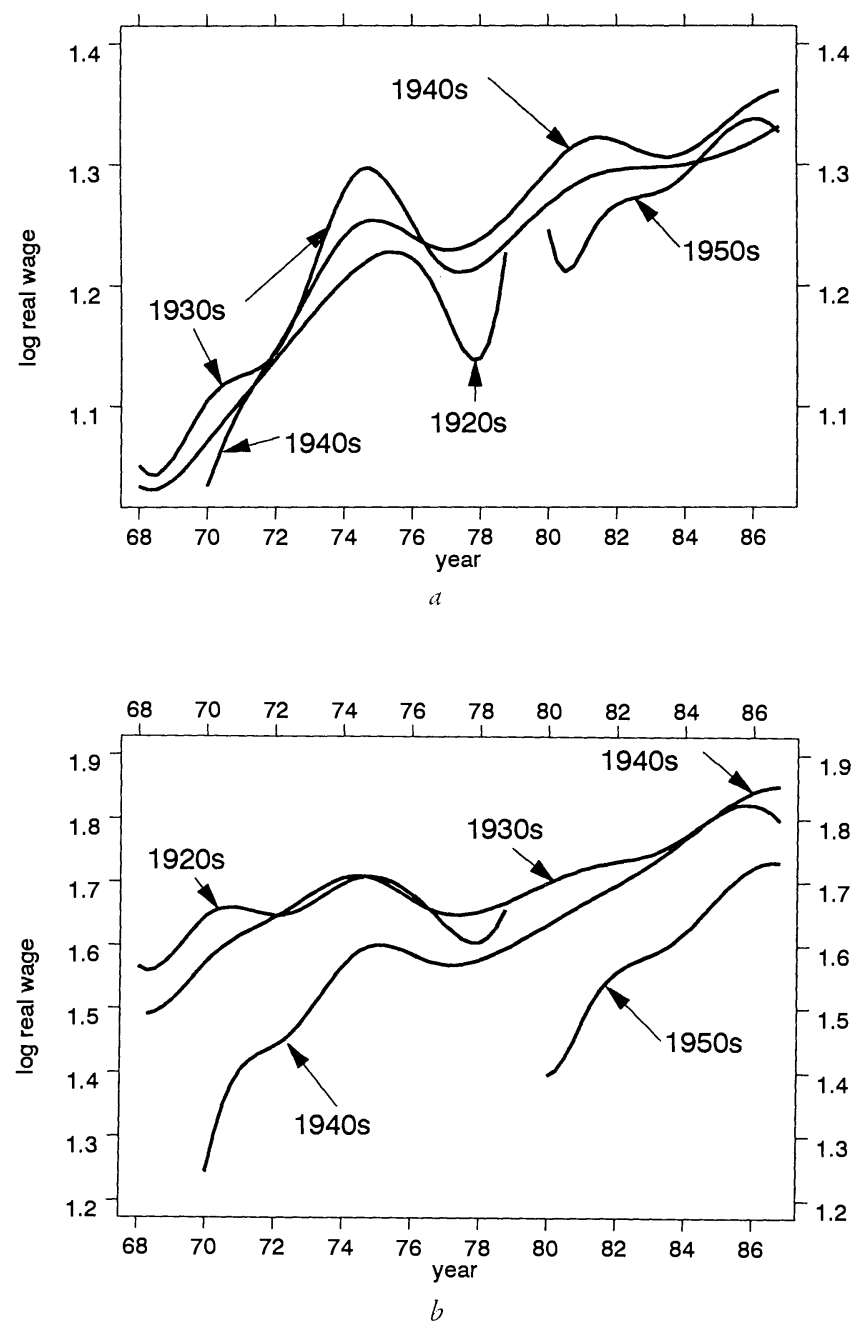

Fig. 2.--Log hourly wage by cohort and year. $a$, Manual and clerical workers; $b$, professional and managerial workers.

Table 2

Average Age Workers Left Full-Time Education by Cohort and Occupation

\begin{tabular}{cccc}
\hline Cohort & Manual/Clerical & Professional/Managerial & All Occupations \\
\hline $1920 \mathrm{~s}$ & 13.7 & 15.6 & 14.2 \\
$1930 \mathrm{~s}$ & 14.7 & 16.8 & 15.4 \\
$1940 \mathrm{~s}$ & 15.3 & 17.8 & 16.2 \\
$1950 \mathrm{~s}$ & 15.9 & 18.9 & 16.9 \\
\hline
\end{tabular}


In figure 3, we show how the occupational pay differential changes over time for each cohort: the differentials are quite similar for the first two cohorts but much lower for the last two (1940s and 1950s cohorts). For the latter two, these differentials increase over time, and toward the end of the sample period differentials tend to converge across the three remaining groups. Thus the average occupational differential in the whole sample is increasing from 1980 onward, mainly due to increasing differentials among younger workers (from a low base). Ignoring cohort effects, this gives a U-shaped path for the occupational differential with the minimum around 1980.

In figures $4 a$ and $4 b$, respectively, we present a graph of selected quantiles of the log wage distribution and the interdecile range of log wages over time. All percentiles shown (tenth, twenty-fifth, fiftieth, seventy-fifth, and ninetieth) grow in real terms over the sample period. This contrasts with the United States, where the lowest percentiles are actually falling (see MaCurdy and Mroz 1991; Murphy and Welch 1992; Juhn, Murphy, and Pierce 1993). This might be due to the fact that in the United Kingdom the social security benefits have a wider coverage and did not fall overall in real terms during the 1980s. This may effectively constrain the wages of the lowest skill workers from falling, at the expense of employment. Nevertheless, dispersion is increasing in the United Kingdom because the median and the quantiles above it are growing at a faster rate than those below. The interdecile range (fig. $5 a$ and $5 b$ ) is higher for the professional/ managerial workers than the manual/clerical group, but it does not grow over time. In contrast, during the 1980s this measure of dispersion increased for the manual/clerical workers. An important component of the increased

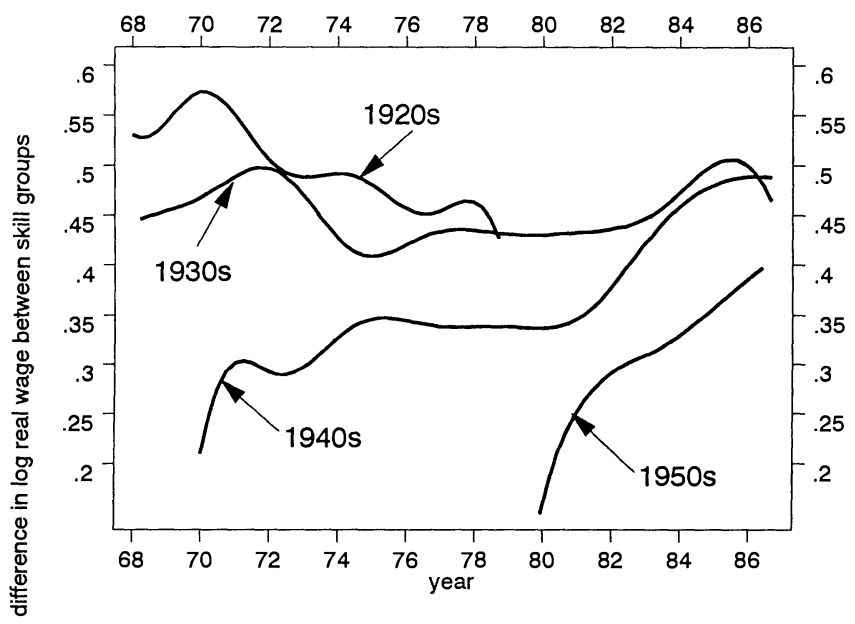

FIG. 3.-Occupational pay differential by cohort and time: log wage premium for professional and managerial workers over manual and clerical. 

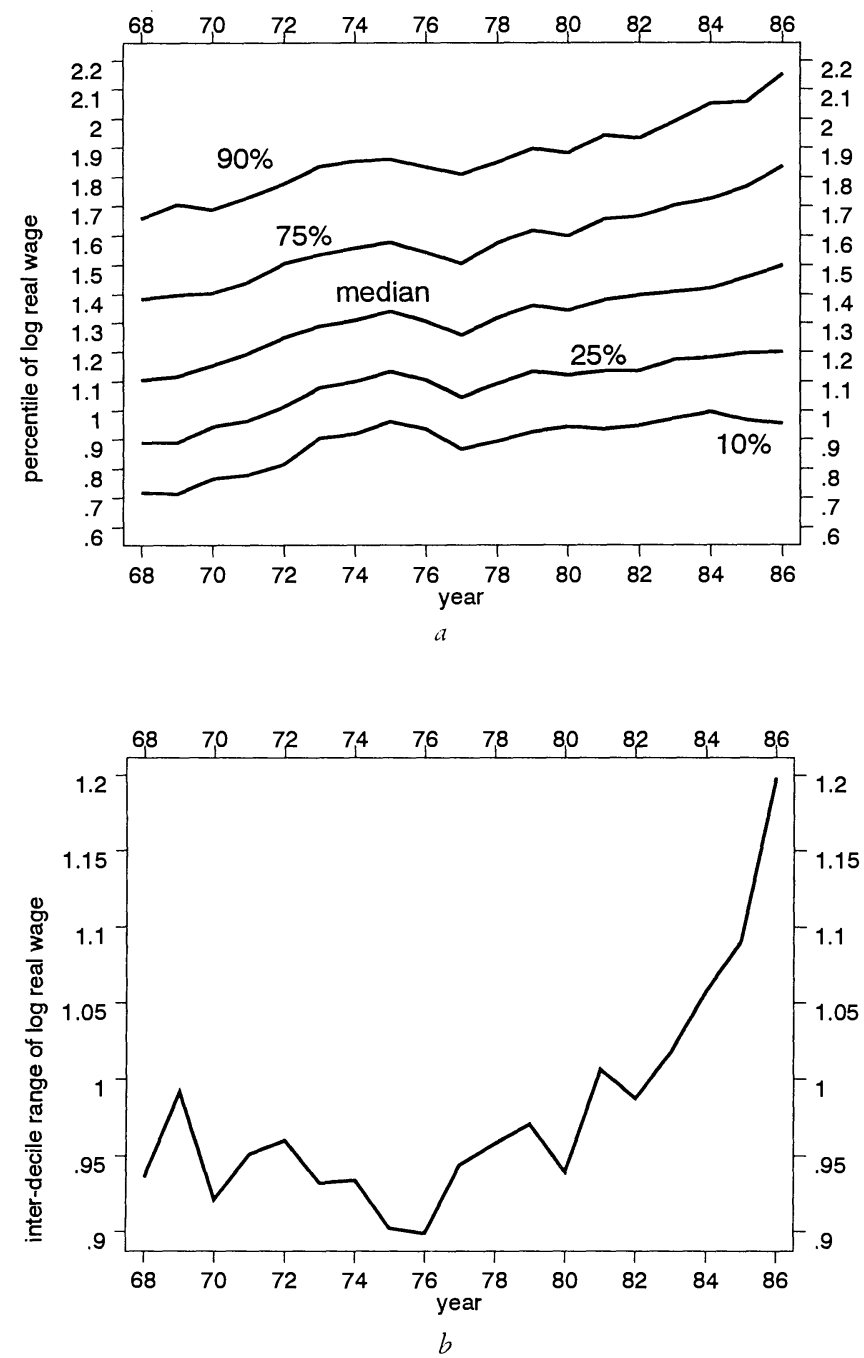

FIG. 4.-Log hourly wages over time. $a$, Percentiles of the distribution; $b$, interdecile range.

dispersion of wages is therefore increased dispersion within the manual and clerical occupation group.

The data show a steady occupational upgrading of the labor force, which is consistent with the increased level of education between cohorts. In figure 6 we present the proportion of manual and clerical workers by cohort over time, which clearly shows a steady decline. The observed changes are both within cohort and over time for each cohort. The fact that older cohorts are more likely to have manual/clerical jobs 


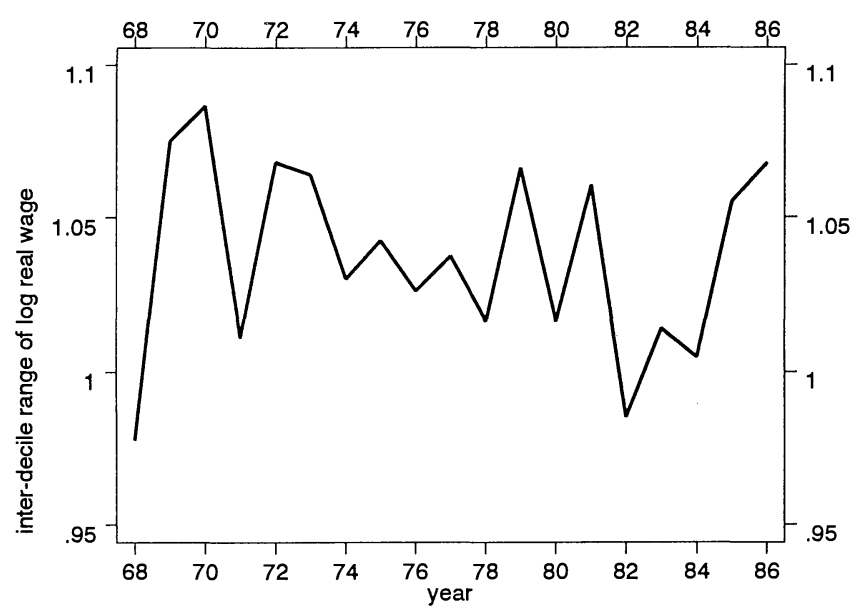

$a$

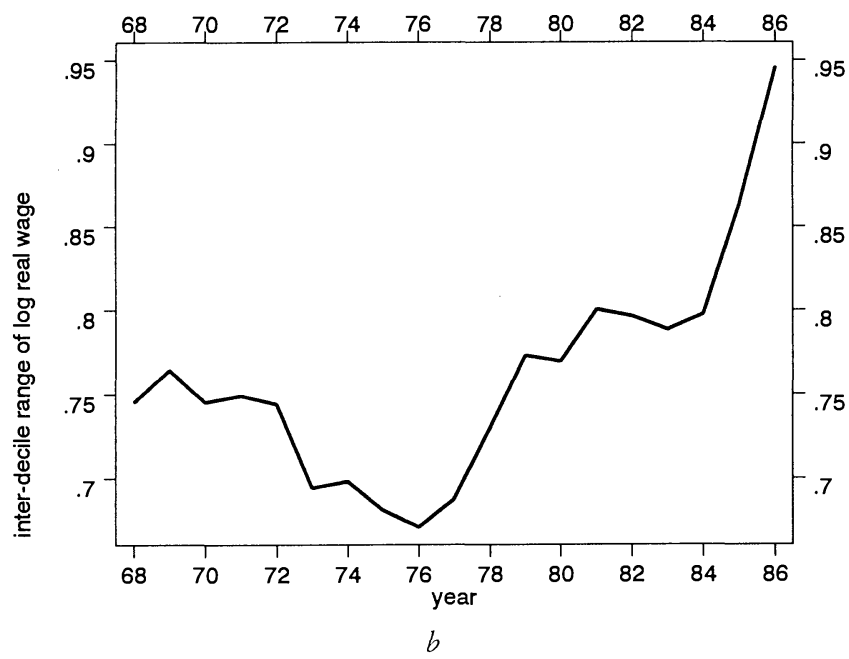

Frg. 5.-Interdecile range of log hourly wages over time. a, Professional and managerial occupations; $b$, manual and clerical occupations.

than younger workers is consistent with the increase in the average education level (table 2). The changes in occupational composition over time (for a given cohort) reflect both job promotion over the life cycle and compositional effects due to the fall in male employment. To illustrate this, we ran two linear regressions, one for workers and one for nonworkers. The dependent variable in both cases was the proportion of manual and clerical workers, which we regressed on a linear trend 


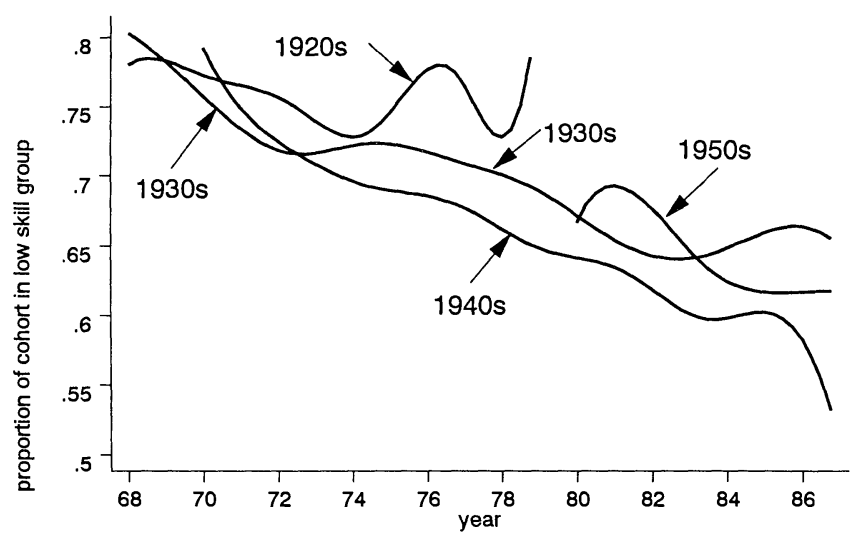

FIG. 6.-Proportion of cohort in manual and clerical occupations over time

and cohort dummies. This showed that on average, the proportion of these workers falls by 0.5 percentage points for the unemployed and 0.9 percentage points for the employed each year. ${ }^{10}$ Thus a sizeable part of the change in the proportion of manual/clerical workers can be interpreted as promotions toward professional/managerial occupations. ${ }^{11}$ The fall in the proportion of the manual/clerical workers, taken together with the increases in dispersion among this group, may have mitigated the overall increase in observed wage dispersion.

Figure 7 illustrates the employment experience of each cohort. Employment has fallen steadily for all generations, particularly during the 1980-82 recession. The youngest cohort (born in the 1950s) seems to be the hardest hit, with their employment remaining lowest even at the end of the sample period. Otherwise, there do not seem to be any systematic differences between cohorts at each point in time. Nevertheless this fall in employment could have important composition effects on wages. It is primarily the lower-wage individuals who are becoming unemployed. ${ }^{12}$ This should bias wages toward displaying countercyclical (or less procyclical) behavior and could reduce observed dispersion among workers.

${ }^{10}$ We observe the skill level of all but $10 \%$ of the unemployed. Their skill categorization is based on their previous job.

${ }^{11}$ When we looked within the manual/clerical group, the same trend prevailed: the proportion of manual workers in unskilled jobs fell relative to the rest.

${ }^{12}$ It is not possible to correct for these composition effects without further structural assumptions, i.e., without the availability of an instrument that has significant explanatory power for employment and that can be excluded from the wage equation. 


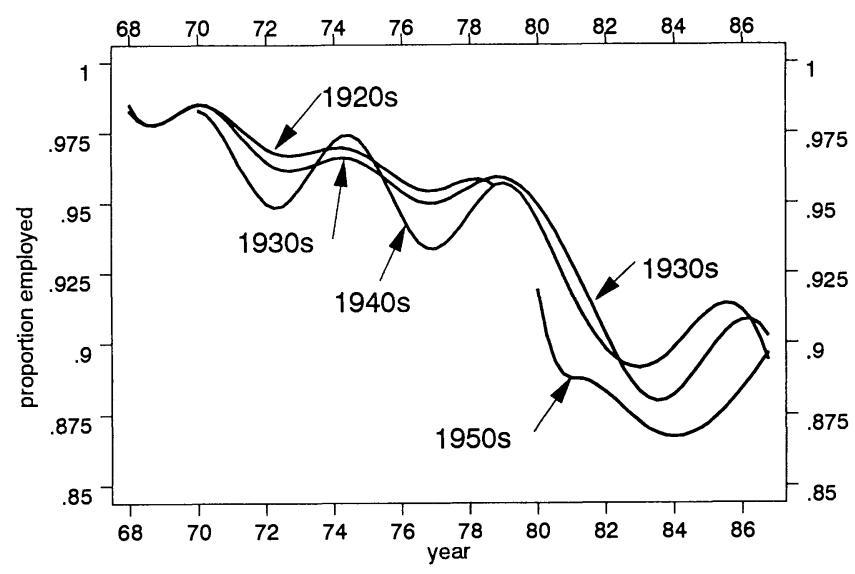

FIG. 7.-Proportion of cohort employed over time

\section{Regression Results}

We now turn to the results obtained by estimating equation (1). We use two estimation methods. In the first, we use instrumental variables on the original repeated cross-section data; here we control only for the possible endogeneity of the unemployment rate. To the extent that occupational choice is correlated with omitted idiosyncratic characteristics affecting productivity, the estimated effects will be driven both by the actual occupational pay differential as well as by the effects of the unobservables. In the second, we use the grouping technique, which controls for these unobserved characteristics. As detailed earlier, the dependent variable in this case is the average log wage of the cohort, and the manual/clerical dummy on the right-hand side of equation (1) is replaced by its proportion in the cohort at time period $t$. In both sets of results we allow for the endogeneity of the unemployment rate using the U.S. unemployment rate lagged by one year as an instrument. The coefficient on the unemployment rate is restricted to be constant across cohorts.

The results are presented in table 3 . Columns i, iii, and $\mathrm{v}$ correspond to the ungrouped results, and columns ii and iv to the grouped estimates. The estimated effect of the unemployment rate on wages is always negative and highly significant, implying that individual real wages are procyclical. The estimates imply that a 1 percentage point increase in the unemployment rate leads ceteris paribus to a $1.4 \%$ fall in real wages. These results are remarkably close to those obtained by Solon, Bartsky, and Parker (1994) using the U.S. Panel Study of Income Dynamics. Their ordinary least squares (OLS) estimate, which uses data over the same time period and a similar specification of time trends, is also -1.4. Both sets of results control 
Table 3

Wage Equations by Cohort

\begin{tabular}{|c|c|c|c|c|c|}
\hline & (i) & (ii) & (iii) & (iv) & (v) \\
\hline Unemployment & $\begin{array}{r}-1.41980 \\
(48178)\end{array}$ & $\begin{array}{r}-1.4017 \\
(.4877)\end{array}$ & $\begin{array}{r}-1.41403 \\
(.48077)\end{array}$ & $\begin{array}{r}-1.4589 \\
(.4776)\end{array}$ & $\begin{array}{r}-1.31215 \\
(.49495)\end{array}$ \\
\hline \multirow{2}{*}{\multicolumn{6}{|c|}{$\begin{array}{c}\text { Life-cycle profiles- } \\
\text { professional/ } \\
\text { managerial: } \\
\text { 1920s cohort: }\end{array}$}} \\
\hline & & & & & \\
\hline Constant & $\begin{array}{c}175.42661 \\
(2.36081)\end{array}$ & $\begin{array}{l}183.9863 \\
(12.8683)\end{array}$ & $\begin{array}{r}171.86144 \\
(2.44925)\end{array}$ & $\begin{array}{l}153.2456 \\
(21.9788)\end{array}$ & $\begin{array}{r}171.48787 \\
(2.49448)\end{array}$ \\
\hline Trend & $\begin{array}{l}.42393 \\
(.05675)\end{array}$ & $\begin{array}{l}.4150 \\
(.0599)\end{array}$ & $\begin{array}{l}.18799 \\
(.07876)\end{array}$ & $\begin{array}{r}-1.3932 \\
(1.0944)\end{array}$ & $\begin{array}{l}.18290 \\
(.07928)\end{array}$ \\
\hline \multicolumn{6}{|l|}{ 1930s cohort: } \\
\hline Constant & $\begin{array}{r}174.75105 \\
(1.96035)\end{array}$ & $\begin{array}{r}161.5852 \\
(7.5943)\end{array}$ & $\begin{array}{r}174.73015 \\
(1.96047)\end{array}$ & $\begin{array}{r}159.5066 \\
(7.8446)\end{array}$ & $\begin{array}{r}174.38367 \\
(1.99574)\end{array}$ \\
\hline Trend & $\begin{array}{l}.37024 \\
(.08699)\end{array}$ & $\begin{array}{c}.4088 \\
(.0866)\end{array}$ & $\begin{array}{c}.37587 \\
(.08785)\end{array}$ & $\begin{array}{l}1.6054 \\
(.3583)\end{array}$ & $\begin{array}{c}.35923 \\
(.08956)\end{array}$ \\
\hline Trend $^{2}$ & $\begin{array}{l}.01269 \\
(.00909)\end{array}$ & $\begin{array}{c}.0159 \\
(.0095)\end{array}$ & $\begin{array}{l}.01262 \\
(.00909)\end{array}$ & $\begin{array}{l}.0147 \\
(.0092)\end{array}$ & $\begin{array}{c}.01170 \\
(.00915)\end{array}$ \\
\hline Trend $^{3}$ & $\begin{array}{c}.00061 \\
(.00024)\end{array}$ & $\begin{array}{l}.0007 \\
(.0003)\end{array}$ & $\begin{array}{c}.00061 \\
(.00024)\end{array}$ & $\begin{array}{l}.0009 \\
(.0003)\end{array}$ & $\begin{array}{c}.00060 \\
(.00024)\end{array}$ \\
\hline Spline & $\begin{array}{c}-.00069 \\
(.00040)\end{array}$ & $\begin{array}{c}-.0009 \\
(.0004)\end{array}$ & $\begin{array}{c}-.00068 \\
(.00040)\end{array}$ & $\begin{array}{c}-.0010 \\
(.0004)\end{array}$ & $\begin{array}{r}-.00065 \\
(.00040)\end{array}$ \\
\hline \multicolumn{6}{|l|}{ 1940s cohort: } \\
\hline Constant & $\begin{array}{r}164.81770 \\
(1.94181)\end{array}$ & $\begin{array}{c}162.8971 \\
(9.0900)\end{array}$ & $\begin{array}{r}163.66396 \\
(1.92341)\end{array}$ & $\begin{array}{c}162.6898 \\
(9.3918)\end{array}$ & $\begin{array}{r}162.32801 \\
(2.14704)\end{array}$ \\
\hline Trend & $\begin{array}{l}.47095 \\
(.08461)\end{array}$ & $\begin{array}{c}.4740 \\
(.0885)\end{array}$ & $\begin{array}{l}.67721 \\
(.08721)\end{array}$ & $\begin{array}{l}.5777 \\
(.4173)\end{array}$ & $\begin{array}{l}.60279 \\
(.09824)\end{array}$ \\
\hline Trend $^{2}$ & $\begin{array}{l}.03602 \\
(.00863)\end{array}$ & $\begin{array}{l}.0360 \\
(.0087)\end{array}$ & $\begin{array}{l}.03610 \\
(.00863)\end{array}$ & $\begin{array}{c}.0366 \\
(.0087)\end{array}$ & $\begin{array}{c}.04024 \\
(.00879)\end{array}$ \\
\hline Trend $^{3}$ & $\begin{array}{l}.00189 \\
(.00030)\end{array}$ & $\begin{array}{l}.0019 \\
(.0003)\end{array}$ & $\begin{array}{l}.00194 \\
(.00030)\end{array}$ & $\begin{array}{c}.0019 \\
(.0003)\end{array}$ & $\begin{array}{c}.00206 \\
(.00031)\end{array}$ \\
\hline Spline & $\begin{array}{c}-.00226 \\
(.00043)\end{array}$ & $\begin{array}{c}-.0023 \\
(.0004)\end{array}$ & $\begin{array}{c}-.00232 \\
(.00043)\end{array}$ & $\begin{array}{c}-.0023 \\
(.0005)\end{array}$ & $\begin{array}{r}-.00244 \\
(.00044)\end{array}$ \\
\hline \multicolumn{6}{|l|}{ 1950s cohort: } \\
\hline Constant & $\begin{array}{r}127.89821 \\
(6.77768)\end{array}$ & $\begin{array}{l}138.3959 \\
(11.3034)\end{array}$ & $\begin{array}{r}114.05900 \\
(6.80210)\end{array}$ & $\begin{array}{c}69.2855 \\
(32.8247)\end{array}$ & $\begin{array}{r}114.69575 \\
(6.81610)\end{array}$ \\
\hline Trend & $\begin{array}{l}2.63328 \\
(.71765)\end{array}$ & $\begin{array}{l}2.5336 \\
(.6994)\end{array}$ & $\begin{array}{l}3.21125 \\
(.70746)\end{array}$ & $\begin{array}{c}5.2104 \\
(1.2614)\end{array}$ & $\begin{array}{l}3.10167 \\
(.71764)\end{array}$ \\
\hline Trend $^{2}$ & $\begin{array}{c}-.03086 \\
(.01274)\end{array}$ & $\begin{array}{r}-.0299 \\
(.0122)\end{array}$ & $\begin{array}{c}-.03242 \\
(.01239)\end{array}$ & $\begin{array}{l}-.0386 \\
(.0116)\end{array}$ & $\begin{array}{r}-.03073 \\
(.01253)\end{array}$ \\
\hline \multicolumn{6}{|l|}{$\begin{array}{c}\text { Occupational pay } \\
\text { differentials: } \\
\text { 1920s cohort: }\end{array}$} \\
\hline Manual/clerical & $\begin{array}{r}-50.52834 \\
(1.09399)\end{array}$ & $\begin{array}{r}-62.0638 \\
(17.8072)\end{array}$ & $\begin{array}{r}-45.85732 \\
(1.59819)\end{array}$ & $\begin{array}{l}-21.1986 \\
(29.9977)\end{array}$ & $\begin{array}{r}-45.85913 \\
(1.59811)\end{array}$ \\
\hline $\begin{array}{l}\text { Manual/clerical } \\
\times \text { trend }\end{array}$ & $\cdots$ & $\cdots$ & $\begin{array}{c}.30768 \\
(.06594)\end{array}$ & $\begin{array}{c}2.3689 \\
(1.4332)\end{array}$ & $\begin{array}{l}.30780 \\
(.06593)\end{array}$ \\
\hline $\begin{array}{l}\text { 1930s cohort: } \\
\text { Manual/clerical }\end{array}$ & $\begin{array}{r}-45.40722 \\
(.78972)\end{array}$ & $\begin{array}{r}-26.9270 \\
(10.3191)\end{array}$ & $\begin{array}{r}-45.40612 \\
(.79016)\end{array}$ & $\begin{array}{c}-23.8516 \\
(10.5237)\end{array}$ & $\begin{array}{r}-45.40552 \\
(.79031)\end{array}$ \\
\hline $\begin{array}{l}\text { Manual/clerical } \\
\times \text { trend }\end{array}$ & $\cdots$ & $\cdots$ & $\begin{array}{r}-.00977 \\
(.03556)\end{array}$ & $\begin{array}{r}-1.7570 \\
(.5003)\end{array}$ & $\begin{array}{r}-.00972 \\
(.03557)\end{array}$ \\
\hline $\begin{array}{l}\text { 1940s cohort: } \\
\text { Manual/clerical }\end{array}$ & $\begin{array}{r}-36.16937 \\
(.92494)\end{array}$ & $\begin{array}{r}-33.4015 \\
(12.8782)\end{array}$ & $\begin{array}{r}-34.51357 \\
(.59460)\end{array}$ & $\begin{array}{r}-32.8262 \\
(13.4010)\end{array}$ & $\begin{array}{r}-33.33886 \\
(.75352)\end{array}$ \\
\hline
\end{tabular}


Table 3 (Continued)

\begin{tabular}{|c|c|c|c|c|c|}
\hline & (i) & (ii) & (iii) & (iv) & (v) \\
\hline $\begin{array}{l}\text { Manual/clerical } \\
\times \text { trend }\end{array}$ & $\ldots$ & $\ldots$ & $\begin{array}{c}-.30542 \\
(.03105)\end{array}$ & $\begin{array}{r}-.1401 \\
(.5961)\end{array}$ & $\begin{array}{r}-.18182 \\
(.05522)\end{array}$ \\
\hline $\begin{array}{l}\text { Manual/clerical } \\
\times \text { linear } \\
\text { spline in } \\
1980\end{array}$ & $\ldots$ & $\cdots$ & $\ldots$ & $\ldots$ & $\begin{array}{r}-.34837 \\
(.12674)\end{array}$ \\
\hline $\begin{array}{l}\text { 1950s cohort: } \\
\text { Manual/clerical }\end{array}$ & $\begin{array}{r}-31.23232 \\
(1.56471)\end{array}$ & $\begin{array}{c}-44.8532 \\
(12.7676)\end{array}$ & $\begin{array}{r}-11.63560 \\
(3.15429)\end{array}$ & $\begin{array}{c}51.4329 \\
(47.8500)\end{array}$ & $\begin{array}{r}-11.63793 \\
(3.15505)\end{array}$ \\
\hline $\begin{array}{l}\text { Manual/clerical } \\
\times \text { trend }\end{array}$ & $\cdots$ & $\ldots$ & $\begin{array}{c}-.76885 \\
(.12846)\end{array}$ & $\begin{array}{c}-3.3595 \\
(1.5797)\end{array}$ & $\begin{array}{r}-.76880 \\
(.12849)\end{array}$ \\
\hline
\end{tabular}

NOTE.-See Sec. V for discussion. The dependent variable is the log real hourly wage rate. All coefficients and standard errors have been multiplied by 100 and hence should be interpreted as percentage effects. "Trend" grows by one each quarter and is equal to -36 in the first quarter of 1968. "Manual/clerical" is a dummy variable that is one when the worker is a manual/clerical worker. The linear spline is equal to D1 $2 \times($ trend -12$)$, where D12 is one after the first quarter of 1980 . Columns i, iii, and v are estimated on the original cross-section data without any grouping. Columns ii and iv are produced using the grouped data. In all cases, the unemployment rate is instrumented using the U.S unemployment rate lagged 1 year. The standard errors (shown in parentheses) allow for heteroscedasticity and for correlated shocks across individuals.

for occupational composition, although in a different way owing to differences in data.

We investigated the extent to which the wages of manual/clerical workers were more or less sensitive to business-cycle fluctuations than those of the professional/managerial group. The difference between the coefficients was never significant. The $t$-value for the interaction between the manual/ clerical dummy and the unemployment rate was around one for all models. The point estimates implied that wages of the manual/clerical workers were slightly more procyclical.

When we do not allow for the endogeneity of the unemployment rate, we find a smaller coefficient $(-1.1, \mathrm{SE}=0.34)$. This is exactly what we would expect if there is any feedback from aggregate wage shocks to unemployment, since the OLS coefficient on the unemployment rate will be biased upward. Nevertheless, the difference of these coefficients is not significant, the $t$-value being only 1.06, and the shape of the age profiles is unchanged between these two estimation methods. The OLS coefficient is very similar to the estimate obtained by Blanchflower and Oswald (1994) for the United Kingdom. If the instruments used for identification are not significant in the reduced form for the variable instrumented, then the results may be biased towards OLS, as shown by Bound, Jaeger, and Baker (1993). In fact, the U.S. unem- 
ployment rate has a $t$-value of 5.2 in the reduced form for U.K. unemployment. ${ }^{13}$

In comparing these results to those obtained using aggregate data, it is important to remember that the measures of average hourly wages based on aggregate earnings are a weighted average of individual wages, the weights being the individuals' hours of work. Depending on whether the latter are procyclical or countercyclical, wages will appear to be more or less procyclical if wages and hours are positively correlated. In addition, as emphasized by Solon et al. (1994), estimates based on aggregate data will suffer from composition bias as the occupation composition changes in the workforce over the cycle. In earlier results, we found that using an aggregate-type measure (i.e., the log of average hourly earnings divided by average hours) constructed from Family Expenditure Survey data (but controlling for occupation composition) exacerbated the estimated procyclical nature of wages because hours are procyclical and positively correlated with wages. ${ }^{14}$

In columns $i$ and ii we compare the results obtained without and with grouping, respectively, assuming that occupational pay differentials are constant over time. First, as discussed in Section III, to validate the grouping method, we need to check that occupation varies between cohorts and time, after controlling for those cohort-specific time trends already included in the wage equation. The $\chi^{2}$ test statistic of the null hypothesis that the occupational changes over time can be explained by these included trends is $296.12(199 \mathrm{df})$, which has a $p$-value of virtually zero, indicating that there is sufficient cross-group variation in occupation for the estimates to be meaningful.

If the occupational variable is positively correlated with omitted variables affecting productivity, then the occupational pay differentials implied by column ii would be lower than those implied by column i. In fact, the results are quite similar, with the coefficients smaller in column ii for the 1930 s and the 1940s cohort and larger for the other two cohorts. None of the differences is significant, and a $4 \mathrm{df} \chi^{2}$ test of the null hypothesis that they are equal is 4.77 , which has a $31.1 \%$-value. The average differential is smaller for younger cohorts.

In the next two columns, we consider whether occupational pay differentials change significantly over time for each cohort, again comparing the grouped results (col. iii) with the ungrouped (col. iv). The relevant coefficients are the ones associated with the variable (trend $\times$ manual/

${ }^{13}$ The reduced form includes on the right-hand side all variables that we treat as exogenous, i.e., the average occupational variables and the same trend structure as in eq. (1). We assume that occupation is not correlated with the current aggregate shocks and hence can be treated as predetermined.

${ }^{14}$ See n. 3 above. 
clerical). The sign pattern of the coefficients is similar in both columns, implying that the pay differentials between the manual/clerical and the professional/managerial groups are growing over time for the two younger cohorts, are constant for the 1930s cohort, and are falling for the 1920s cohort. The magnitude of the implied changes is larger for the grouped results. The $8 \mathrm{df}$ test that the coefficients related to occupation are the same between the grouped and the ungrouped results is 20.2 , which has a $p$-value of $1 \%$. Thus the differences are marginally significant, but the parameters from the grouped estimates are quite badly determined. Finally, motivated by the results in the data description section (see fig. 3), in column $\mathrm{v}$ we report estimates including a linear spline for the pay differential for the 1940 s cohort, that is, D12 $\times($ trend -12$) \times($ manual/clerical $)$, where D12 is a dummy that is one after the first quarter of 1980 (when trend $=12$ ), and zero before. This allows a change in the occupational pay differential during the 1980s. We find that the differential increases at a significantly higher rate in the 1980 s than before, but it is still slower than the rate of increase of the occupational pay differential for the younger 1950 s cohort $(-0.53$ percentage points a quarter, compared to -0.77 points for the 1950s cohort).

The main implication of these results is that pay differentials were falling for younger generations at the point of labor market entry, but that the differentials increased significantly over the 1980s, particularly for the two younger cohorts. The pay differentials for the 1930s cohort always remained high and did not increase significantly during the 1980s, while for the 1920 s cohort, differentials were being slightly compressed during the 1970 s. The fall of the differential for younger cohorts at labor market entry partly reflects two related compositional effects: the average level of education is rising, and the proportion of unskilled manual workers within the manual/ clerical group is falling for younger cohorts. As a result, the average skill level within this group is higher among the younger cohorts relative to the older ones. Another factor may be the increased unemployment rate among the manual workers in the 1980s, which would also raise the quality of the manual/clerical workers relative to the professional/managerial ones.

\section{Cohort and Occupation-Specific Age Profiles of Wages}

We now turn to the evolution of wages over time for each of the four cohorts in our sample, having removed the cyclical effects caused by unemployment. The relevant coefficients for the age profiles are shown in table 3. In the analysis that follows we use the coefficients of column v.

In figure 8, we plot the time profiles of log wages for each cohort averaged over the whole sample. Some of the changes over time reflect the changes in occupational composition. All four cohorts experience substantial wage growth during this period. We observe two of the four cohorts at their time of entry (the 1940s cohort in 1970 and the 1950s cohort in 1980). In 


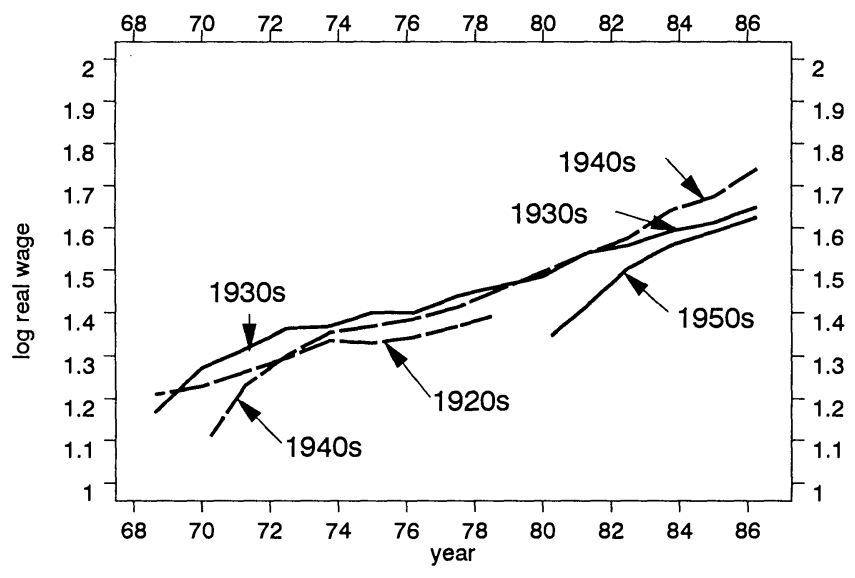

FIG. 8.-Fitted time profile of log hourly wage by cohort

both cases their average entry wage is $17 \%$ lower than the preceding cohort. This cohort wage differential quickly disappears, and about 4 years after entry the recent entrants are paid virtually the same on average as their seniors. Returns to experience are visible only relative to new entrants; otherwise the cross-section profiles are totally flat.

These profiles are presented separately for each occupation group in figures $9 a$ and $9 b$. The majority of the population is in manual/clerical occupations, although this has been declining steadily. Wage growth and wage levels are lower for the manual/clerical workers, reflecting the estimated pay differentials. The cross-section profiles for the manual/clerical workers are completely flat, the younger cohorts being paid virtually the same as the older cohorts. This could imply that there are no experience effects, but another plausible explanation is that the increasing quality and level of education for individuals classified as manual/clerical workers in younger cohorts counteracts the experience effects of older individuals. This interpretation is supported by two facts: first, the increase in the proportion of skilled manual workers vis-à-vis unskilled for younger cohorts (as well as over time within cohorts), and, second, the extension of compulsory schooling, meaning that the manual/clerical workers have an increased average level of education in younger cohorts.

Figure $9 b$ shows that the entry-level wages for both the 1940s and 1950s cohorts were significantly below those of the incumbents for professional/ managerial workers. After entry, wages grow quickly, eroding the initial experience premium of the incumbents. At older ages, comparing the $1920 \mathrm{~s}$ cohort with the 1930s in the 1970s, and the 1930s with the 1940s cohort in the 1980s, the cross-section differences disappear.

There are two important conclusions from these results. First, the observable experience premia, as reflected by the differences across cohorts 


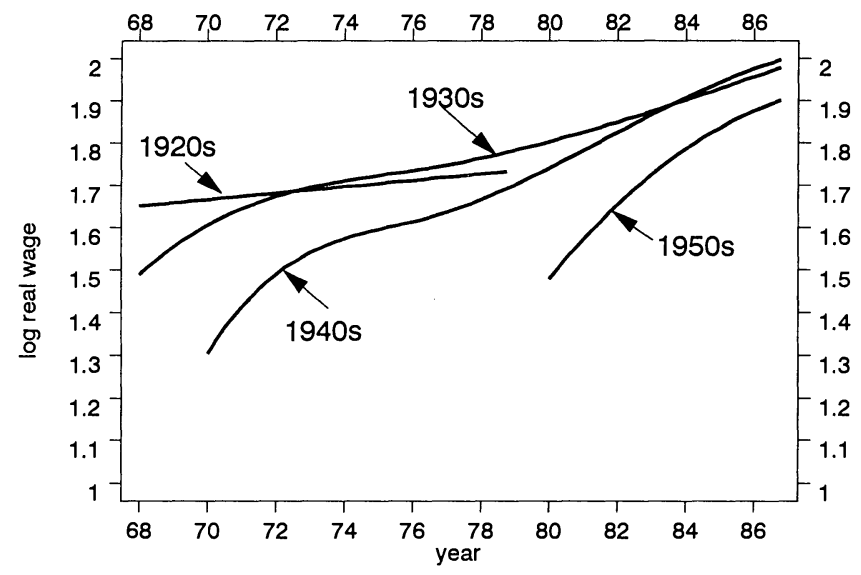

$a$

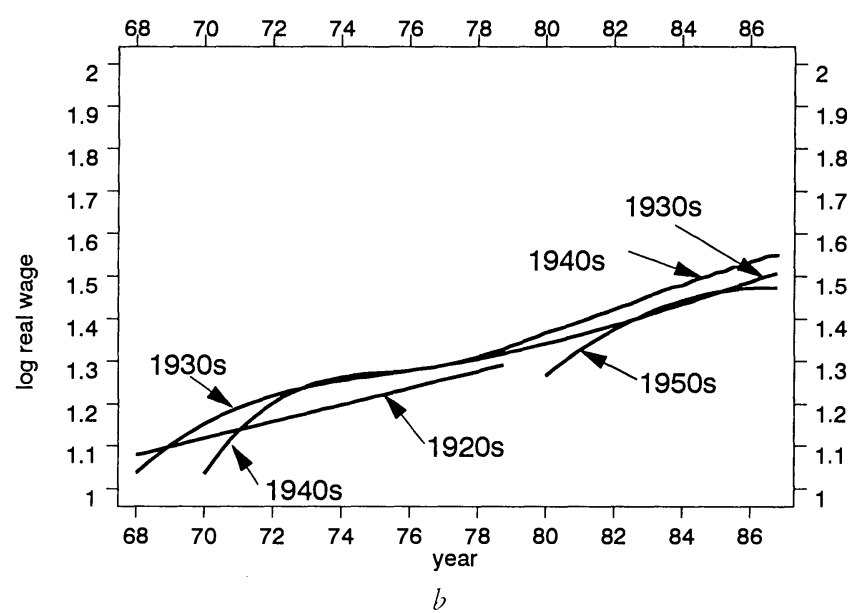

FIG. 9.-Fitted time profile of log hourly wage by cohort. $a$, Professional and managerial occupations; $b$, manual and clerical occupations.

at a point in time, did not change in the United Kingdom over this time period; this is clearly visible both when we look at the entire population and when we consider each occupation group separately. Second, experience premia are relatively high only for the professional/managerial workers, and mainly at younger ages. This feature is present both in the 1970s and in the 1980s. The absence of experience effects among the manual/clerical workers may be partly attributable to the changing quality and quantity of schooling received by younger workers in these occupations, which ceteris paribus will push up their wages. 
We simulated the implications of these estimates for wage dispersion using the model in column $\mathrm{v}$. The model captures the wage compression of the late 1960s and the early 1970s. In the 1980s, the model predicts a very small increase in dispersion fully attributable to the increasing pay differentials, but the change in dispersion is mitigated by the changing occupational composition toward more professional/managerial workers. The main part of increased dispersion is within the manual/clerical group and is not explicable by changes in the means of the separate groups. The model estimated with grouped data (col. iv) gives higher estimated changes in pay differentials and predicts a greater increase in dispersion in the 1980s, although the results are not as well determined.

\section{Conclusions}

This article estimates wage equations for separate cohort and occupation groups. Our wage measure is the hourly wage.

The main conclusions of the results are:

1. Wages are highly procyclical. A 1 percentage point increase in unemployment leads, ceteris paribus, to a $1.4 \%$ fall in real wages. Ignoring the endogeneity of aggregate unemployment rates for the wage equation tends to reduce the estimate of this effect.

2. The cross-section profiles of wages are very flat, indicating either that the premium to experience is very low or that it is counteracted by the attributes of younger cohorts. This result is particularly strong for the manual/clerical group, forming at least $60 \%$ of the sample. Among the professional/managerial group, we find that entry-level wages are about $17 \%$ lower than those of workers who have been in the labor market 10 years longer. The entrants catch up within 5 or 6 years, after which point they are paid about the same as the previous cohort. This pattern does not change between the 1970s and the 1980s.

3. The pay differential between professional/managerial workers and manual/clerical workers is lower for younger cohorts, close to labor market entry, probably reflecting the better education received by the latter. This occupational pay differential increases with time for the younger cohorts but is constant or decreasing for the older ones. The average sample pay differential falls until about 1979 and starts to rise thereafter. Our conclusions on pay differentials based on the original cross-section data were not significantly different to those obtained using grouped data. One implication is that the changes in the pay differentials we observe reflect an increased demand for workers in professional/managerial occupations.

4. When we simulate the implications of this model, our results imply that the main source of increasing wage dispersion observed in the United Kingdom is not the divergence between professional/managerial and man$\mathrm{ual} / \mathrm{clerical}$ workers but an increase in dispersion among the younger 
members of the latter group. The changing occupational composition of the workforce mitigates the increase in dispersion.

\section{Appendix}

\section{The Grouping Estimator}

To illustrate the econometric methodology, we consider the following wage equation:

$$
\ln w_{i t}=\beta^{\prime} x_{i t}+u_{i t},
$$

where $u_{i t}$ represents shocks to wages that may be correlated across individuals (common shocks) and with some of the $x_{i t}$ either because of measurement error or because of, say, self-selection.

To estimate the model, we construct averages by quarter and by date of birth group to obtain a pseudopanel, and we use least squares on these transformed data. The grouped equation has the form

$$
[\overline{\ln w}]_{c t}=\beta^{\prime}[\bar{x}]_{c t}+[\bar{u}]_{c t}
$$

where a bar represents the average of the variable within the group defined by the subscripts $c$ (cohort) and $t$ (time). The error term $[\bar{u}]_{c t}$ represents the common shocks across members of the cohort. It would be zero if all shocks are purely idiosyncratic.

The method can be given an instrumental variables interpretation; the validity of the procedure depends on whether the variable by which we group is uncorrelated with the error term and on whether the data exhibit sufficient variability after grouping. Denote by $Z$ the matrix containing all cohort dummies interacted with time dummies, by $P_{z}$ the projection $Z\left(Z^{\prime} Z\right)^{-1} Z^{\prime}$ and by $X$ the stacked matrix of regressors. The cohort estimator is simply $\hat{\beta}=\left(X^{\prime} P_{z} X\right)^{-1} X^{\prime} P_{z} y=\left(\bar{X}^{\prime} D \bar{X}\right)^{-1} \bar{X}^{\prime} D \bar{y}$, where $\bar{X}$ and $\bar{y}$ are cohort averages of the original data and $D$ is a diagonal weight matrix where each element is the number of individuals in each cohort and quarter. If we assume that aggregate shocks are not correlated across time or cohorts, the asymptotic covariance matrix of $\hat{\beta}$,

$$
V=\left(X^{\prime} P_{z} X\right)^{-1}\left(X^{\prime} P_{z} \Omega P_{z} X\right)\left(X^{\prime} P_{z} X\right)^{-1},
$$

can be estimated by replacing $X^{\prime} P \Omega P X$ by

$$
W=\sum_{c} \sum_{t} \bar{x}_{c t}\left[\sum_{i \in c} \sum_{j \in c}\left(\hat{v}_{i t} \hat{\hat{v}}_{j t}\right)\right] \bar{z}_{c t}^{\prime}=\sum_{c} \sum_{t} \bar{x}_{c t}\left[\left(\bar{v}_{c t} \bar{v}_{c t}^{\prime} d_{c t}^{2}\right)\right] \bar{x}_{c t}^{\prime}
$$


where $c$ is an index over cohorts, $t$ is an index over time, $i$ and $j$ are indices over individuals within a cohort, $\bar{x}_{c t}$ is the cohort mean of the right-hand-side variables, $\hat{v}_{i t}$ is the residual from the $i$ th individual observed in period $t$ (this covariance matrix estimator is analogous to the one developed by White [1980]), $d_{c t}$ is the number of observations in cell $(c, t)$, and $\bar{v}_{c t}$ is the average residual over the cohort. ${ }^{15}$

Grouping controls for the potential correlation of $x_{i t}$ with all individualspecific components in the error term (fixed over time or not) and for additive measurement error. With aggregate shocks, it is possible that variables such as economy-wide unemployment rates would be correlated with the cohort-specific shock to wages $[\bar{u}]_{c t}$, which is the average (over individuals) of $u_{i t}$, making unemployment rates endogenous for individuallevel equations. In such a case, we can use a standard instrumental variables procedure with lags of the grouped $x_{i t}$ 's and lags of the macroeconomic variables as instruments. ${ }^{16}$ Given this, the general ideas presented above do not change; the estimator becomes $\beta^{\text {giv }}$ $=\left(\bar{X}^{\prime} D \bar{R}\left(\bar{R}^{\prime} D \bar{R}\right)^{-1} \bar{R}^{\prime} D \bar{X}\right)^{-1} \bar{X}^{\prime} D \bar{R}\left(\bar{R}^{\prime} D \bar{R}\right)^{-1} \bar{R}^{\prime} D \bar{y}$, where $D \bar{R}$ is the matrix of (weighted - grouped) instruments assumed orthogonal to $[\bar{u}]_{c t}$. At the cross-section level, the instrument matrix is simply $Z \bar{R}$. The covariance matrix of this estimator is again estimated in a similar fashion.

\section{References}

$\rightarrow$ Angrist, Joshua, D. "Grouped Data Estimation and Testing in Simple Labor Supply Models." Journal of Econometrics 47 (1991): 243-66.

$\rightarrow$ Bils, Mark. "Real Wages over the Business Cycle: Evidence from Panel Data." Journal of Political Economy 93 (1985): 666-89.

Blanchflower, David, G., and Oswald, Andrew, J. "Estimating a Wage Curve for Britain, 1973-90.” Economic Journal 104 (September 1994): 1025-43.

$\rightarrow$ Blank, Rebecca, M. "Why Are Wages Cyclical in the 1970s?" Journal of Labor Economics 8 (January 1990): 16-47.

Bound, John; Jaeger, David, A.; and Baker, Regina. "The Cure Can Be Worse than the Disease: A Cautionary Tale regarding Instrumental Variables." Technical Paper no. 137. Cambridge, MA: National Bureau of Economic Research, June 1993.

Bound, John, and Johnson, George. "Changes in the Structure of Wages in the 1980's: An Evaluation of Alternative Explanations." American Economic Review 28 (June 1992): 371-92.

$\rightarrow$ Deaton, Angus. "Panel Data from Time Series of Cross-Sections." Journal of Econometrics 30 (1985): 109-26.

Farebrother, R. W. "A Grouping Test for Misspecification." Econometrica 47 (January 1979): 209-10.

${ }^{15}$ It is possible to generalize this covariance matrix estimator for the case where there is limited serial correlation.

${ }^{16}$ In the presence of common shocks, the asymptotics have to be done both with large $T$ and large $N$. Moreover, suitable stationarity conditions have to assumed. The estimator will be $\sqrt{T}$ consistent and asymptotically normal. 
Goodman, Alisa, and Webb, Stephen. "For Richer, for Poorer: The Changing Distribution of Income in the UK, 1961-1991." Commentary no. 42. London: Institute for Fiscal Studies, 1994.

Heckman, James, J., and Robb, Richard. "Alternative Identifying Assumptions in Econometric Models of Selection Bias." In Advances in Econometrics, vol. 5, edited by Truman F. Bewley, pp. 243-87. Cambridge: Cambridge University Press, 1987.

Juhn, Chinhui; Murphy, Kevin, M.; and Pierce, Brooks. "Wage Inequality and the Rise in the Returns to Skill." Journal of Political Economy 101 (June 1993): 410-42.

$\rightarrow$ Keane, Michael; Moffitt, Robert; and Runkle, David. "Real Wages over the Business Cycle: Estimating the Impact of Heterogeneity with Microdata." Journal of Political Economy 96 (1988): 1232-66.

MaCurdy, Thomas, E., and Mroz, Thomas, A. "Measuring Macroeconomic Trends in Wages from Cohort Specifications." Unpublished manuscript. Standford, CA: Stanford University, 1991.

$\rightarrow$ Murphy, Kevin, M., and Welch, Finis. "The Structure of Wages." Quarterly Journal of Economics 107 (February 1992): 285-326.

Schmitt, Peter. "The Changing Structure of Earnings in Britain, 1974-88." Working Paper no. 223. London: Centre for Economic Performance, April 1992.

$\rightarrow$ Solon, Gary; Bartsky, Robert; and Parker, Jonathan, A. "Measuring the Cyclicality of Wages: How Important Is Composition Bias?" Quarterly Journal of Economics 109 (February 1994): 1-25.

$\rightarrow$ Wald, Abraham. "The Fitting of Straight Lines If Both Variables Are Subject to Errors." Annals of Mathematical Statistics 11 (1940): 284-300.

White, Halbert. "A Heteroscedasticity Consistent Covariance Matrix Estimator and a Direct Test for Heteroskedasticity." Econometrica 48 (May 1980): 817-38. 